\title{
A Morphological Mutant of \\ Paracoccidioides brasiliensis Strain IVIC Pb9. Isolation and Wall Characterization
}

\author{
By F. SAN-BLAS, GIOCONDA SAN-BLAS AND L. J. COVA \\ Instituto Venezolano de Investigaciones Científicas, \\ Centro de Microbiología y Biología Celular, Apartado I827, Caracas, Venezuela
}

(Received I I March I975; revised I4 August I975)

\begin{abstract}
SUMMARY
A morphological mutant of Paracoccidioides brasiliensis strain IVIC Pb9 was isolated after treatment of the yeast-like $(\mathrm{Y})$ form with nitrosoguanidine. Colonies of the mutant grown at room temperature did not show the whitish cotton-like morphology typical of the mycelial form of the parental strain. Y-cells were much smaller than those produced by the parent and grew forming chains of different sizes. The main chemical difference in the wall of the Y-form was the replacement of the $\alpha$-I,3-glucan, typical of the parental strain, by an amorphous 1,3 -mannan in the mutant.
\end{abstract}

\section{INTRODUCTION}

Paracoccidioides brasiliensis, an imperfect fungus pathogenic to humans, undergoes thermal dimorphism (Nickerson, 1948). It develops a yeast-like (Y) form when grown at $37^{\circ} \mathrm{C}$ and a mycelial (M) form at room temperature. Although both forms have been extensively studied by chemical and electron microscopic studies (Drouchet \& Tapater, 1954; Carbonell \& Rodriguez, I965; Carbonell, 1969), the mechanism by which transformation takes place is not understood.

Quantitative analysis of the walls of both $\mathrm{Y}$ and $\mathbf{M}$ forms have shown that their chemical compositions are similar (Kanetsuna et al., 1969) but that their glucans differ. $\alpha-\mathrm{I}, 3-$ Glucan has been reported as the main glucose polymer in the $\mathrm{Y}$-form, while in the $\mathrm{M}$-form this polysaccharide is replaced by a $\beta$-1,3-glucan (Kanetsuna et al., 1972). These authors assumed that the spherical shape of the Y-like form of $P$. brasiliensis is due to the short rod-like fibres characteristic of the $\alpha$-I,3-glucan and that the long narrow fibres of the $\beta$-I,3glucan contribute to the mycelial form.

This paper describes a morphological mutant of the Y-form of $P$. brasiliensis strain IVIC Pb9 in which the fibrillar $\alpha-\mathrm{I}, 3$-glucan is substituted by an amorphous $\mathrm{I}, 3$ mannan. The cell wall of the yeast-like form of the parental strain $P$. brasiliensis IVIC Pb9 had a different chemical composition from that reported by Kanetsuna et al. (I969).

\section{METHODS}

Organism and growth conditions. Paracoccidioides brasiliensis strain IVIC Pb9, a human isolate (formerly strain 7193 of the Instituto Nacional de Tuberculosis, Caracas, Venezuela), has been maintained in our laboratory on Sabouraud Liquid Broth Modified (BBL) agar for several years. Exponentially-growing populations of the Y-form of this strain were 
obtained by inoculating two loopfuls of a 3 -day-old culture, from a Sabouraud agar slant kept at $37^{\circ} \mathrm{C}$, into $500 \mathrm{ml}$ Erlenmeyer flasks containing $100 \mathrm{ml}$ of brain-heart infusion broth (BHI), from BBL. Slants were subcultured at least io times every 3 days (San-Blas \& Cova, 1975).

Mutagenesis and isolation of mutants. A late-exponential culture of the Y-form of P. brasiliensis IVIC Pb9, containing $10^{6}$ colony forming units (c.f.u.)/ml in $100 \mathrm{ml} \mathrm{BHI,} \mathrm{was}$ centrifuged, washed three times with $100 \mathrm{ml}$ of $\mathrm{O} \cdot \mathrm{I}$ M-citrate buffer $\mathrm{pH} 5$ and resuspended in I00 ml of this buffer with $50 \mu \mathrm{g}$ of $N^{\prime}$-methyl- $N^{\prime}$-nitro- $N$-nitrosoguanidine (NTG) (Sigma). The mixture was incubated in a $500 \mathrm{ml}$ Erlenmeyer flask at $37^{\circ} \mathrm{C}$ on a gyratory shaker for $30 \mathrm{~min}$, centrifuged and washed three times in the same buffer to remove NTG. The pellet was next resuspended in $100 \mathrm{ml}$ of fresh BHI broth and further incubated at $37^{\circ} \mathrm{C}$ to allow expression of any mutant phenotype. After $72 \mathrm{~h}$ incubation, $\mathrm{O} \cdot \mathrm{I} \mathrm{ml}$ portions of $10^{-1}$ and $10^{-2}$ dilutions of the culture were plated on GGY agar plates (Nickerson \& Edwards, 1949) by the soft-agar-layer technique. Plates were incubated at $37{ }^{\circ} \mathrm{C}$ for 10 days to allow good growth of the colonies. Plates containing between 50 and 200 colonies were then further incubated at room temperature to allow transformation to the $\mathbf{M}$-form. Plates were inspected several times over a period of 2 months to check for any possible variation from the wildtype morphology of the M-form colonies. Any M-form colony differing in morphology from the parental strain was allowed to transform back to the Y-form at $37^{\circ} \mathrm{C}$ on Sabouraud Liquid Broth Modified agar slants.

Purification of mutants. Once transformation to the Y-form was obtained, a loopful of the suspected mutant was inoculated into $5 \mathrm{ml} \mathrm{BHI} \mathrm{broth} \mathrm{and} \mathrm{incubated} \mathrm{at} 37^{\circ} \mathrm{C}$. After $72 \mathrm{~h}$ incubation, portions from the cultures were diluted in $0.85 \%(\mathrm{w} / \mathrm{v}) \mathrm{NaCl}$ and plated out on GGY agar and incubated at $37^{\circ} \mathrm{C}$. When good colony growth was observed, plates were transferred to room temperature to allow transformation of the colonies. Some of the colonies which showed the altered phenotype were again transformed to the Y-form and treated as above, until all colonies derived from a single one showed the mutant phenotype.

Preparation and analysis of walls. Both the wild type and the morphological mutant were analysed as described previously (San-Blas \& Carbonell, 1974). The walls were separated into three fractions: an alkali-insoluble residue (fraction I); an alkali-soluble fraction, precipitated by neutralization with acetic acid (fraction 2); and an alkali-soluble fraction, not precipitated by neutralization with acetic acid (fraction 3). Thin-layer chromatography using the developing system described by Lato et al. (I 968) replaced paper chromatography. Release of formic acid in periodate-oxidized samples $(25 \mathrm{mg}$ samples suspended in $25 \mathrm{ml}$ of $30 \mathrm{~mm}-\mathrm{NaIO}_{4}$ ) was followed by titration against I mM-NaOH. The uptake of periodic acid was followed by the spectrophotometric method of Aspinall \& Ferrier (1957). The preparation of wall fractions for electron microscopy has been described elsewhere (SanBlas \& Carbonell, 1974). Yeast mannan was prepared according to San-Blas \& Cunningham (1974) and used for comparisons.

Sources of enzymes. $\alpha$-I,3-Glucanase (EC. 3.2.I group) and $\beta$-I,3-glucanase (EC. 3.2 . . 6) were prepared from Cladosporium resinae and Basidiomycetes QM806, respectively, according to Reese \& Mandels (1959). These exoenzymes were tested against $\beta$-I,3-glucan from Aspergillus niger and $\beta$-I,3-glucan from $P$. brasiliensis Pb9 (San-Blas \& Carbonell, 1974).

Enzymic procedures. All glucose-containing samples were incubated with either $\alpha$ - or $\beta$-I,3-glucanase. The sample containing the equivalent of I $\mathrm{mg}$ of glucose was mixed with $\mathrm{I} \mathrm{mg}$ of $\alpha$ - or $\beta$-I,3-glucanase in I $\mathrm{ml}$ of $0.05 \mathrm{M}$-acetate buffer $\mathrm{pH} 5.0$. The mixture was 
Table I. Chemical composition of walls from yeast-like ( $Y$ ) forms of P. brasiliensis, strains IVIC Pby and IVIC Pbi40

The amount of each class of compound is expressed as a percentage of either the cell wall or the three fractions derived from it.

\begin{tabular}{|c|c|c|c|}
\hline \multirow{2}{*}{\multicolumn{4}{|c|}{ IVIC Pb9* }} \\
\hline & & & \\
\hline Hexoses & $38 \cdot 4$ & $4 I \cdot 5$ & $36 \cdot 5$ \\
\hline Amino sugars & $43 \cdot 4$ & 30.0 & $44 \cdot I$ \\
\hline Amino acids & 10.1 & 17.0 & $14: 3$ \\
\hline Lipids & I I $\cdot 0$ & 10.0 & $5 \cdot 0$ \\
\hline \multicolumn{4}{|l|}{ Fraction I } \\
\hline Yield $\ddagger$ & $40 \cdot 0$ & $4 I \cdot 5$ & $84 \cdot 7$ \\
\hline Hexoses & 19.0 & $16 \cdot 9$ & $34 \cdot 3$ \\
\hline Amino sugars & $44^{\circ} 0$ & $60 \cdot 5$ & $52 \cdot 7$ \\
\hline Amino acids & 20.6 & $16 \cdot 2$ & II $\cdot 9$ \\
\hline \multicolumn{4}{|l|}{ Fraction 2} \\
\hline Yield $\ddagger$ & $45 \cdot 0$ & $3 \cdot 2$ & $3 \cdot 4$ \\
\hline Hexoses & $100 \cdot 0$ & $100 \cdot 0$ & 93.0 \\
\hline Amino sugars & 0.0 & 0.0 & 0.0 \\
\hline Amino acids & 0.0 & 0.0 & $6 \cdot 7$ \\
\hline \multicolumn{4}{|l|}{ Fraction 3} \\
\hline Yield $\ddagger$ & $5 \cdot 0$ & $55 \cdot 3$ & II $\cdot 3$ \\
\hline Hexoses & $25 \cdot 0$ & 20.4 & $22 \cdot 3$ \\
\hline Amino sugars & 0.0 & 0.0 & 0.0 \\
\hline Amino acids & 0.0 & $19 \cdot 2$ & $16 \cdot 8$ \\
\hline Lipids & - & $60 \cdot 0$ & $60 \cdot 7$ \\
\hline
\end{tabular}

* As reported by Kanetsuna \& Carbonell (1970) and Kanetsuna et al. (1972).

$\dagger$ As found during the course of this work, after several years of subculturing in vitro.

† Fraction as a percentage of the weight of the wall.

incubated at $37^{\circ} \mathrm{C}$ for $0,0.5, \mathrm{I}, 2,4,6$ or $24 \mathrm{~h}$. At the indicated times, $0 . \mathrm{I} \mathrm{ml}$ of the reaction mixture was heated at $100{ }^{\circ} \mathrm{C}$ for $5 \mathrm{~min}$ to inactivate the enzyme. After adjusting the volume to I $\mathrm{ml}$ and filtering, the liberated glucose was estimated by the Somogyi method for reducing sugar (Somogyi, I952).

\section{RESULTS}

During the procedure for the mutant isolation, I250 Y-form colonies on GGY plates surviving the mutagenesis treatment were examined periodically for up to 8 weeks' incubation at room temperature. About $2 \%$ of the surviving Y-form colonies assayed for transformation did not show the whitish cotton-like morphology typical of the M-form of the wild-type colonies of $P$. brasiliensis (Restrepo, 1970), although they adhered to the agar surface and were composed of compact interwoven mycelia. The mycelium appeared typical upon examination by phase contrast in smears. Those colonies which apparently differed from the parental strain IVIC Pb9 only in the morphology of the M-colonies, were chosen as presumptive mutants for further tests. Samples from each of these colonies were allowed to transform back to the Y-form at $37^{\circ} \mathrm{C}$. After one cycle of purification, half of these presumptive mutants gave $\mathrm{M}$-form colonies showing the cotton-like appearance of the parental strain. M-form colonies from the remaining half retained their altered morphology through several purification cycles. One of these mutants, identified as strain IVIC PbI40, was selected for further studies. M-form colonies of this mutant showed a brownish brain-like morphology, lacking typical aerial mycelia and submerged growth (Fig. I), as opposed to the 

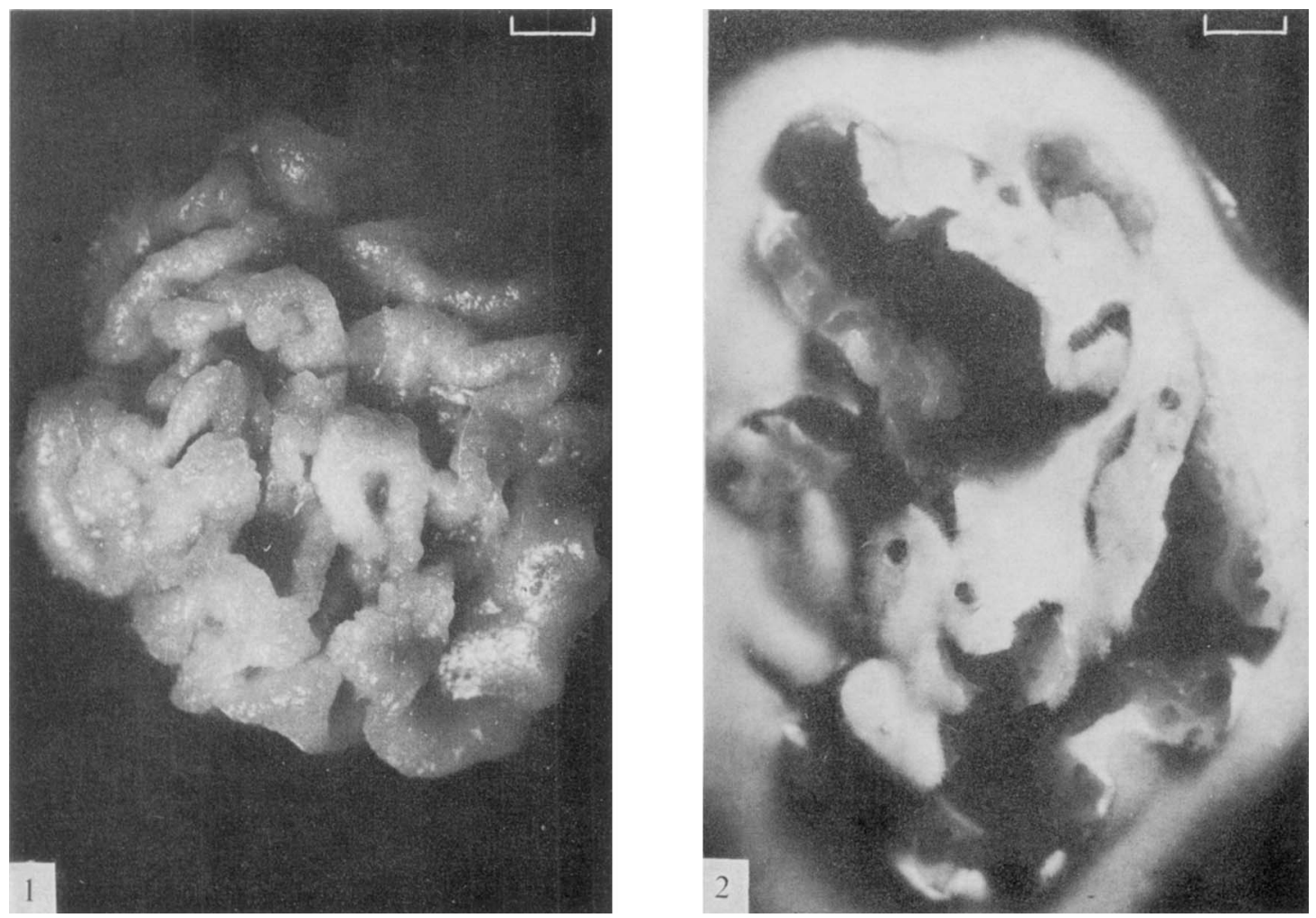

Fig. I. Four-week-old M-like colony of $P$. brasiliensis IVIC PbI40 grown on Sabouraud agar at $22{ }^{\circ} \mathrm{C}$. Bar marker represents $2 \mathrm{~mm}$.

Fig. 2. Four-week-old M-like colony of $P$. brasiliensis IVIC Pb9 grown on Sabouraud agar at $22{ }^{\circ} \mathrm{C}$. Bar marker represents $2 \mathrm{~mm}$.

M-form colonies of the parental strain (Fig. 2). Reversion to the wild-type morphology was not observed. Y-form colonies on Sabouraud agar were brain-like and easily detachable from the agar surface, resembling those of the parental strain IVIC Pb9 (Carbonell \& Rodriguez, 1965). Strain IVIC PbI40 was a slow-growing form in BHI broth and formed clumps, a typical feature of $P$. brasiliensis growing under the same conditions. However, the presence of an appreciable number of true colonies in the form of lifeboats was observed. They were similar to those usually observed in some wild-type colonies grown on agar plates at the same temperature. The formation of these colonies in broth was probably due to the fact that Y-like cells of this mutant tended to remain in chains growing in several directions (Fig. 3). These Y-like cells were much smaller than those of IVIC Pb9 (Fig. 4), and were round or oval with diameters of I to $3 \mu \mathrm{m}$. Most cells remained attached to one another, forming chains of different sizes. Cells showing multiple peripheral buds with the appearance of a ship's wheel were also observed.

Chemical analysis of walls and their alkali-extracted fractions produced the following results:

Whole walls. Table I summarizes the differences in chemical composition of $P$. brasiliensis IVIC Pb9 and IVIC PbI40, and includes figures reported by Kanetsuna et al. (I972) for $P$. brasiliensis IVIC Pb9. Paper chromatography of total acid hydrolysates of wall preparations 

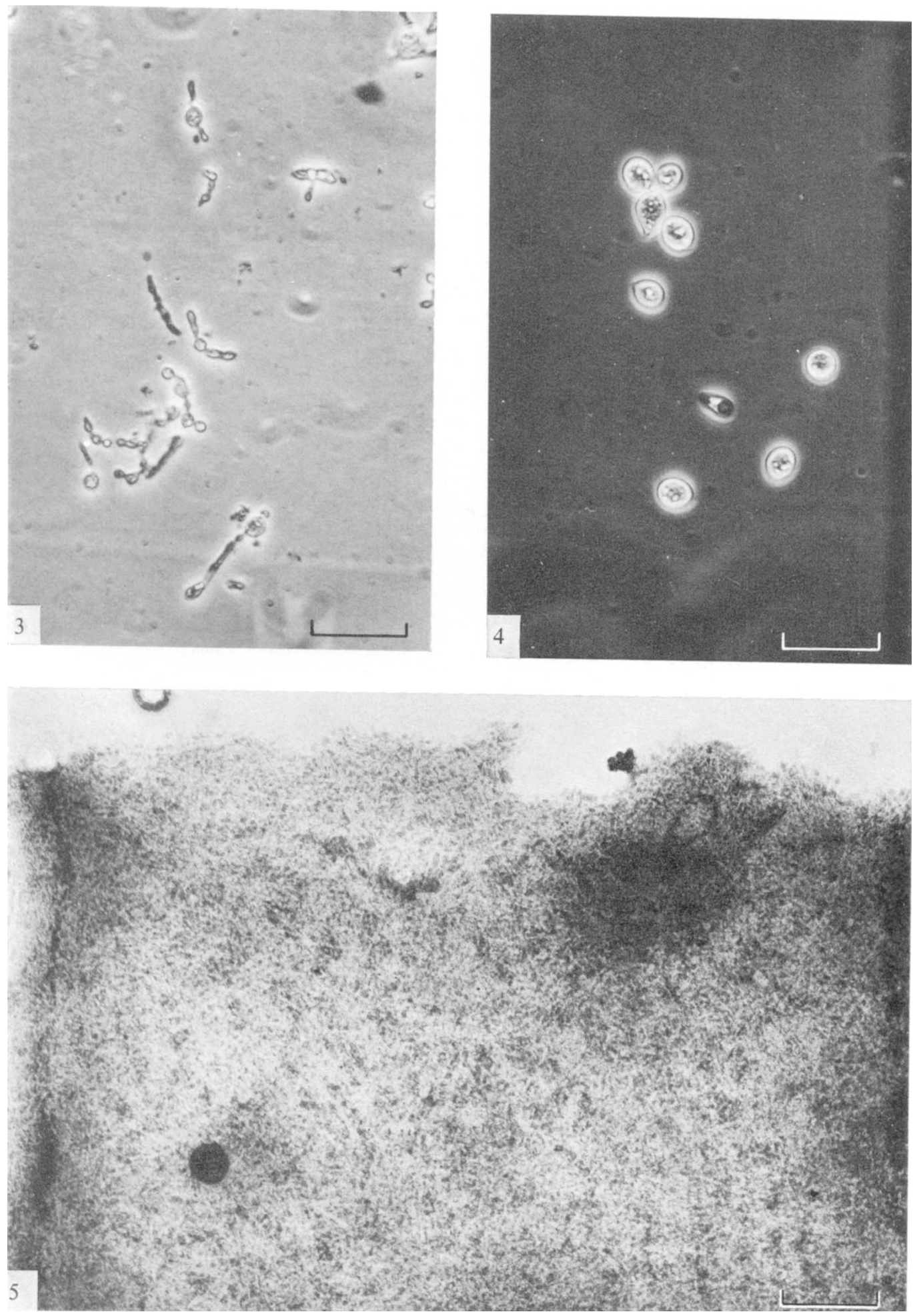

Fig. 3. Y-like cells of P. brasiliensis IVIC PbI40 grown in $\mathrm{BHI}$ broth at $37^{\circ} \mathrm{C}$. Bar marker represents I0 $\mu \mathrm{m}$.

Fig. 4. Y-like cells of $P$. brasiliensis IVIC Pb9 grown in BHI broth at $37^{\circ} \mathrm{C}$. Bar marker represents I0 $\mu \mathrm{m}$.

Fig. 5. Negatively-stained fraction I from P. brasiliensis IVIC Pb9. A similar arrangement was 


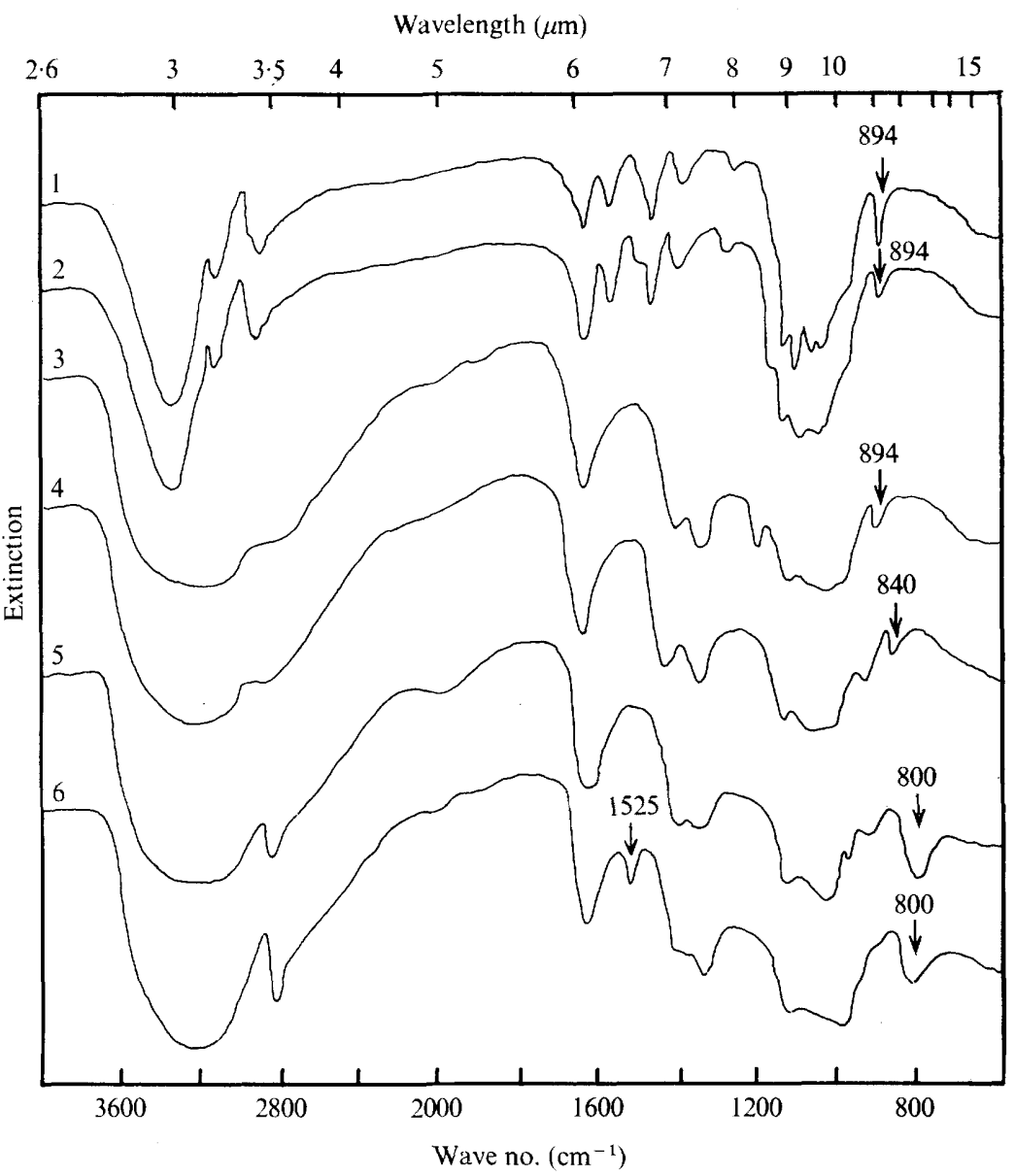

Fig. 6. Infrared absorption spectra of fungal polysaccharides. (I) Chitin; (2) fraction I from $P$. brasiliensis IVIC Pb9 and IVIC PbI40; (3) laminarin; (4) $\alpha$-I,3-glucan from $P$. brasiliensis IVIC Pb9; (5) mannan from Hansenula holstii; (6) I,3-mannan from P. brasiliensis IVIC PbI40.

showed the presence of glucose, galactose and mannose in both strains. Lipids appeared to be present in higher amounts in the parental strain than in the mutant, whereas both strains had similar amounts of amino sugars and amino acids. Shadowed electron micrographs of strain IVIC PbI 40 cell walls showed a fibrillar arrangement similar to that already described for IVIC Pb9 (Carbonell, I972).

Fraction I. Although the mutant strain contained twice as much fraction I as the parental strain, the composition was similar (Table I). Hydrolysates contained 50 to $60 \%$ of the total fraction as amino sugars, which when analysed by paper chromatography showed only glucosamine. Infrared absorption of this fraction produced a pattern which corresponded to that of chitin (Fig. 6), with an absorption band at $890 \mathrm{~cm}^{-1}$; characteristic of $\beta$-linkages in glucans.

Thin-layer chromatography showed glucose as the main neutral sugar in both preparations, with traces of galactose. Digestion of fraction I from either strain with $\beta$-I,3-glucanase released all the glucose residues as glucose, suggesting that this occurred as $\beta$-I,3-glucan. 
Table 2. Sugars in the walls of P. brasiliensis IVIC Pb9 and IVIC PbI40 (yeast-like form)

\begin{tabular}{cl} 
& \multicolumn{1}{c}{ IVIC Pb9 } \\
Fraction I & $\begin{array}{l}\text { Glucose as } \beta \text {-I,3-glucan } \\
N \text {-acetylglucosamine as chitin } \\
\text { Traces of galactose }\end{array}$ \\
Fraction 2 & $\begin{array}{l}\text { Glucose as } \alpha \text {-I,3-glucan } \\
\text { Fraction 3 }\end{array}$ \\
& $\begin{array}{l}\text { Galactose and mannose as } \\
\text { galactomannan } \\
\text { Traces of glucose }\end{array}$
\end{tabular}

\author{
IVIC PbI40 \\ Glucose as $\beta$ - 1,3 -glucan \\ $N$-acetylglucosamine as chitin \\ Traces of galactose \\ Mannose as 1,3-mannan \\ Glucose and galactose (polymeric \\ association not studied)
}

Amino acids were also present in similar amounts in both preparations although it was not determined whether they were discrete proteins or glycoproteins.

Electron micrographs (Fig. 5) showed fibrils shorter than those described by Carbonell, Kanetsuna \& Gil (I970) for the chitin and $\beta$-I,3-glucan of the parental strain IVIC Pb9.

Fraction 2. Both strains formed about the same amount of this fraction. However, their compositions differed (Table 2). Thin-layer chromatography of an acid hydrolysate from fraction 2 of the parental strain gave a single spot of glucose, shown by enzymic analysis to be exclusively $\alpha-1,3$-linked. Electron micrographs of this fraction showed fibrils which resembled those reported before for $\alpha$-I,3-glucan (San-Blas \& Carbonell, 1974). The mutant strain contained mannose as the only sugar component. Periodate oxidation of this material produced no reaction, suggesting a I,3-mannan. Its anomeric configuration was not determined. The infrared spectrum of this material (Fig. 6) showed a band at $800 \mathrm{~cm}^{-1}$ which has been reported as characteristic of mannans (Michell \& Scurfield, 1970).

Electron micrographs of the mannan found in fraction 2 of the mutant strain showed an amorphous material in which no fibrils could be recognized, unlike the $\alpha$-1,3-glucans.

Fraction 3. The alkali-soluble, non-precipitable fraction of both forms contained proteins and polysaccharides. In fraction 3 of the parental strain, thin-layer chromatography showed the presence of galactose, mannose and traces of glucose, whereas in the mutant strain, glucose and galactose were the only sugars present. The possible linkage between these sugars was not studied. It is also possible that they form complexes with the relatively high amounts of proteins present in this fraction. This material was not organized as a fibrillar structure, being amorphous under the electron microscope.

\title{
DISCUSSION
}

Variations in the morphology of both $\mathrm{Y}$ - and $\mathrm{M}$-form colonies of $P$. brasiliensis grown in vitro are routinely observed and are probably influenced by environmental conditions, although no systematic description of spontaneous variation in colony morphology in $P$. brasiliensis has so far appeared. The same phenomenon often occurs in other dimorphic pathogenic fungi. Berliner \& Burdo (1973) and Berliner (1973) used the effect of continuous light and total darkness to separate Histoplasma capsulatum into two strains (brown and albino) which differ in both morphological and physiological characteristics. An extensive study of the natural variability of Coccidioides immitis has revealed such extreme variations in the morphology of the colonies as to indicate that many of the strains should not have been typed as $C$. immitis (Huppert, Sun \& Bailey, 1967).

The induction of mutants of dimorphic pathogenic fungi has also been demonstrated. In C. immitis, two distinct auxotrophic avirulent mutants of this fungus were obtained after induction of the wild-type prototrophic virulent strain with X-ray irradiation (Foley, 
Berman \& Smith, 1960). The isolation of biochemical and morphological mutants of this fungus was facilitated by the synergistic effects of ultraviolet light and alkylating chemical agents (Walch \& Walch, I967).

The mutant described in this paper, strain IVIC PbI40, was one of several morphological and biochemical mutants which have been isolated in our laboratory and are being characterized.

Y-like cells of $P$. brasiliensis growing in chains are commonly observed when grown at $28^{\circ} \mathrm{C}$, suggesting a transitional morphological state between the $\mathrm{Y}$ - and $\mathrm{M}$-form. The fact that Y-like cells of strain IVIC PbI40 tend to remain in chains at $37^{\circ} \mathrm{C}$ may be due to an altered division process at this temperature. Both these matters will be further investigated.

With regard to the chemical composition of the walls, previous reports (Kanetsuna \& Carbonell, I970; Kanetsuna et al., 1972) indicated that most glucans in the Y-like form of brasiliensis were structured in the $\alpha$-I, 3 -configuration ( $95 \%$ ), 'with only $5 \%$ as $\beta$-I, 3 -glucans (Table I). However, it was observed in our laboratory that during continuous subculturing in vitro of this strain, its pathogenicity decreased and at the same time its cell wall composition varied remarkably. A complete analysis of this strain was then required and results are summarized here for strain IVIC Pb9. This study confirmed that the $\alpha$-I,3-glucan (i.e. the alkali-soluble fraction 2) was reduced. In fact, it declined from $40 \%$ (Kanetsuna et al., 1972) to $3 \%$ of the total cell wall. At the same time, a galactomannan present only in the M-form of $P$. brasiliensis (Kanetsuna et al., 1969) appeared in the Y-like form of strain IVIC Pb9 after subculturing in vitro in such a way that the whole quantity of sugars in the cell wall was about the same for both forms: $39 \%$ (Kanetsuna et al., I969) and $4 \mathrm{I} \cdot 5 \%$ (Table I). Amino sugar and amino acid contents remained almost unchanged in both cases.

According to these results, it seems that the peripheral $\alpha$-I,3-glucan is only required by the fungus when the pathogenic Y-like form is infecting the host, being reduced when continuously subcultured in vitro. Preliminary experiments also suggest that this $\alpha$-1,3-glucan reappears when strain IVIC Pb9 is successfully injected in animals or when it is cultured in medium to which foetal calf serum is added (G. San-Blas, D. Vernet and F. San-Blas, unpublished results). There may be a relationship between this $\alpha$-I,3-glucan and pathogenicity.

On the other hand, the substitution of $\alpha-\mathrm{I}, 3$-glucan by galactomannan in these two strains of IVIC Pb9 may be related to the decrease of pathogenicity observed in the strain extensively cultured in vitro. Azuma et al. (1974) demonstrated the serological activity of galactomannans from various pathogenic fungi, including $P$. brasiliensis; they pointed out that the Y-form of $P$. brasiliensis was devoid of galactomannan and that the galactomannan obtained from the mycelial cells of Histoplasma, Paracoccidioides and Blastomyces species were common antigens of these fungi. Whether the galactomannan found in P. brasiliensis (Yform) after successive subculturing in vitro belongs to the same group of antigens, has still to be investigated.

The composition of the wall of the mutant strain differed from that of the parent strain in that the fibrillar $\alpha-1,3$-glucan was replaced by an amorphous 1,3-mannan. This mannan was recognized not only by chemical analysis such as chromatography and periodate oxidation, but also by infrared spectroscopy of the polymer. Of the features common to all the yeast spectra, the band in the region $8 \mathrm{I} 2$ to $800 \mathrm{~cm}^{-1}$ is the most interesting in relation to mannans. Barker, Bourne \& Whiffen (1956) claimed that it was characteristic of both $\alpha$ and $\beta$-mannans, and Marchessault (1962) regarded its presence in the spectra of polysaccharide mixtures as indicative of mannans. Michell \& Scurfield (I970) confirmed Marchessault's conclusion and showed this band in the spectra of mixtures of mannans 
with various polysaccharides and proteins. The presence of an absorption band at $1530 \mathrm{~cm}^{-1}$ in IVIC PbI40, fraction 2 is also indicative of a protein component (Michell \& Scurfield, 1970), which was revealed in the chemical analysis of its hydrolysates (Table I). The possible linkage between the mannan and this protein was not studied although it is possible that the mannan found in IVIC PbI40 may have such a linkage, like the yeast mannan-protein complex described elsewhere (Sentandreu \& Northcote, I968; León de Pinto \& San-Blas, 1975).

The $\beta$-I,3-glucan present in very low amounts $(5 \%)$ in the $\mathrm{Y}$-like form of the original strain (Kanetsuna et al., 1969) was present in larger amounts in both the parental strain reported here and in the mutant. The $\beta$-I,3-glucan has been described as being responsible for the elongated shape of the mycelium (Kanetsuna et al., 1972). However, the presence of large amounts (about $30 \%$ ) of this polysaccharide in the Y-like forms of the strains studied here cast some doubts on the validity of this assumption.

From the results discussed in this paper, it can be said that mechanisms which regulate the formation of either the yeast-like or the mycelial form in P. brasiliensis are not yet well understood and that further investigation is required in order to elucidate the role of each polysaccharide on these fungal walls.

We are grateful to Miss Domitila Ordaz for technical assistance.

\section{REFERENCES}

Aspinall, G. O. \& FerRier, R. J. (1957). A spectrophotometric method for the determination of periodate consumed during oxidation of carbohydrates. Chemistry and Industry, 1216.

Azuma, I., Kanetsuna, F., TANaka, Y., Yamamura, Y. \& Carbonell, L. M. (1974). Chemical and immunological properties of galactomannans obtained from Histoplasma duboisii, Histoplasma capsulatum, Paracoccidioides brasiliensis and Blastomyces dermatitidis. Mycopathologia et mycologia applicata 54, II I-1 25.

Barker, S. A., Bourne, E. J. \& Whiffen, D. H. (1956). Use of infrared analysis in the determination of carbohydrate structure. In Methods of Biochemical Analysis, vol. 3, pp. 213-245. Edited by D. Glick. New York: Interscience Publishers.

BerLiner, M. D. (I973). Histoplasma capsulatum: vital staining for the differentiation of the albino and brown phenotypes in vitro. Sabouraudia II, 27I-273.

Berliner, M. D. \& Burdo, N. (1973). Effects of continuous light and total darkness on cultures of Histoplasma capsulatum. Sabouraudia Ir, 48-51.

CARBonell, L. M. (1969). Ultrastructure of dimorphic transformation in Paracoccidioides brasiliensis. Journal of Bacteriology 100, $1076-1082$.

CARBonell, L. M. (1972). Ultrastructure of Paracoccidioides brasiliensis in culture. In Paracoccidioidomycosis. Proceeding of the first Panamerican Symposium PAHO,WHO, pp. 21-28. Edited by the Pan American Health Organization (PAHO), Scientific Publication No. 254.

Carbonell, L. M., Kanetsuna, F. \& Gil, F. (1970). Chemical morphology of glucan and chitin in the cell wall of the yeast phase of Paracoccidioides brasiliensis. Journal of Bacteriology Ior, 636-642.

CARBonell, L. M. \& Rodriguez, J. (1965). Transformation of mycelial and yeast forms of Paracoccidioides brasiliensis in cultures and in experimental inoculations. Journal of Bacteriology 9o, 504-510.

Drouchet, E. \& TAPATER, R. C. (I954). Phase levadure et phase filamentous de Paracoccidioides brasiliensis: étude des noyaux. Annales de l'Institut Pasteur 87, 396-403.

Foley, J. M., Berman, R. J. \& SMith, C. E. (1960). X-ray irradiation of Coccidioides immitis arthrospores: survival curves and avirulent mutants isolated. Journal of Bacteriology 79, 480-487.

Huppert, M., Sun, S. H. \& BAILeY, J. W. (1967). Natural variability in Coccidioides immitis. In Proceedings of the Second Coccidioidomycosis Symposium, pp. 323-328. Edited by L. Ajello. Arizona: University of Arizona Press.

Kanetsuna, F. \& Carbonell, L. M. (1970). Cell wall glucans of the yeast and mycelial forms of Paracoccidioides brasiliensis. Journal of Bacteriology nor, 675-680.

Kanetsuna, F., Carbonell, L. M., Azuma, I. \& Yamamura, Y. (1972). Biochemical studies on the thermal dimorphism of Paracoccidioides brasiliensis. Journal of Bacteriology I10, 208-218.

Kanetsuna, F., Carbonell, L. M., Moreno, R. E. \& Rodriguez, J. (i969). Cell wall composition of the yeast and mycelial forms of Paracoccidioides brasiliensis. Journal of Bacteriology 97, 1036-104I. 
Lato, M., Brunelli, B., Ciufinni, G. \& Mezzetti, T. (I 968). Analysis of carbohydrates in biological fluids by means of thin-layer chromatography. Journal of Chromatography 36, 191-I97.

Lfón de Pinto, G. \& San-Blas, G. (I975). Estudios sobre el complejo manán-proteína en Hansenula holstii. Acta cientifica venezolana $25,78-8 \mathrm{I}$.

Marchessault, R. H. (1962). Application of infrared spectroscopy to cellulose and wood polysaccharides. Pure and Applied Chemistry 5, 107-1 29.

Michell, A. J. \& Scurfield, G. (1970). An assessment of infrared spectra as indicators of fungal cell wall composition. Australian Journal of Biological Sciences 23, 345-360.

NiCKerson, W. J. (1948). Enzymatic control of cell division in microorganisms. Nature, London 162, $241-245$.

Nickerson, W. J. \& Edwards, G. A. (1949). Studies on the physiological basis of morphogenesis in fungi. I. The respiratory metabolism of dimorphic pathogenic fungi. Journal of General Physiology 33, 4I-55.

ReEse, E. T. \& MANDEls, M. (1959). $\beta$-D-(I,3)-glucanases in fungi. Canadian Journal of Microbiology $\mathbf{5}$, I73-I 85 .

RESTREPO, A. (1970). A reappraisal of the microscopical appearance of the mycelial phase of Paracoccidioides brasiliensis. Sabouraudia 8, I4I-I 44 .

San-Blas, F. \& Cova, L. J. (I975). Growth curves of the yeast-like form of Paracoccidioides brasiliensis. Sabouraudia I3, 22-29.

San-Blas, G. \& Carbonell, L. M. (1974). Chemical and ultrastructural studies on the cell wall of the yeastlike and mycelial forms of Histoplasma farciminosum. Journal of Bacteriology I r9, 602-6I I.

San-Blas, G. \& Cunningham, W. L. (I974). Structure of cell wall and exocellular mannans from the yeast Hansenula holstii. I. Mannans produced in phosphate-containing medium. Biochimica et biophysica acta 354, 233-246.

Sentandreu, R. \& Northcote, D. H. (I968). The structure of a glycopeptide isolated from the yeast cell wall. Biochemical Journal ro9, 4I9-432.

Somogyi, M. (1952). Notes on sugar determination. Journal of Biological Chemistry 195, 19-23.

Walch, H. \& Walch, R. K. (1967). Studies with induced mutants of Coccidioides immitis. In Proceedings of the Second Coccidioidomycosis Symposium, pp. 339-347. Edited by L. Ajello. Arizona: University of Arizona Press. 